\title{
ARTIGO
}

\section{A pesquisa histórica no ensino: saberes necessários à prática docente}

\section{The historical research in Education: The necessary knowledge for the practice of teaching}

Lídia Eugenia CAVALCANTE ${ }^{1}$

\begin{abstract}
É inútil querer encurtar o caminho e querer começar já sabendo que a voz diz pouco. Pois existe a trajetória, e a trajetória não é apenas um modo de ir. A trajetória somos nós mesmos. Em matéria de viver, nunca se pode chegar antes.
\end{abstract}

Clarisse Lispector

\section{RE S U M O}

\begin{abstract}
Aborda a importância da pesquisa histórica no ensino de graduação e pósgraduação, dos cursos da área de Ciência da Informação, destacando a sua contribuição na formação profissional. Apresenta algumas considerações sobre como a pesquisa histórica contribuirá na relação entre o conhecimento obtido em sala de aula e a prática cotidiana, através de um envolvimento mais dinâmico com a sociedade ao longo do tempo. Destaca, ainda, que nenhum conhecimento, em sua complexidade, é absoluto ou eterno, há sempre uma relação com outros saberes, com novas aquisições do pensamento, ou mesmo de valores. Em conclusão, destaca-se que tais aspectos devem ser observados pelos educadores em sua prática pedagógica, desenvolvendo situações de aprendizagem que permitam aos educandos o exercício do pensamento criativo, autônomo e crítico acerca da realidade discutida em sala.
\end{abstract}

Palavras-chave: pesquisa histórica, ensino, aprendizagem, competência docente, história e Ciência da Informação.

\footnotetext{
1 Professora do Departamento de Ciências da Informação da Universidade Federal do Ceará - UFC. Mestre em História Social UFRJ. Doutoranda em Educação UFC. E-mail: lidia@ufc.br

Recebido e aceito para publicação em 8/7/2003.
} 


\section{A B S T R A C T}

This study focuses on the importance of the historical research at the undergraduate and graduate levels of the Information Science courses, highlighting its contribution to the students' professional education. It considers how the historical research will contribute not only to the knowledge acquired in the classroom, but also to daily practices, creating a more dynamic involvement with society along the process. It also stresses that any knowledge, in its complexity, is neither absolute nor eternal. There is always a relationship with other areas and types of knowledge, with new forms of thinking, even with new values. Thus, these aspects must be observed by educators, who will develop in their work learning situations that will lead learners to creative, autonomous and critical thinking about the realities discussed in class.

Key words: historical research, learning, teaching competence, history and information science.

Este texto inicia-se com um título que, na verdade, é uma afirmação: A Pesquisa histórica no ensino: saberes necessários à prática docente. Mas, também poderia ser apresentado em forma de reflexão/ interrogação: A Pesquisa histórica no ensino: saberes necessários à prática docente? Entretanto, opto pela afirmativa. Porém, deixo o leitor à vontade para fazer a própria escolha e recolher, através deste ensaio, possibilidades de concordâncias ou discordâncias. Sugiro, ainda, a apresentação de reflexões acerca do tema aqui abordado e dos argumentos apresentados, já que este trabalho se destina ao diálogo entre docentes e pesquisadores acerca da pesquisa histórica na prática docente.

Inicialmente, surgem algumas reflexões: para que serve a História? E o ensino de História na área da Ciência da Informação? E, ainda, qual o papel da pesquisa histórica no ensino? A pertinência de tais questionamentos tem por objetivo abrir o diálogo sobre a legitimidade e importância da pesquisa histórica em nosso campo de trabalho na graduação e pós-graduação. Por muito tempo, os currículos de Biblioteconomia privilegiaram, de modo bem especial, as disciplinas cujos conteúdos voltavam-se, de algum modo, para o ensino de História como: Paleografia, Bibliografia, Iconografia e Numismática, constantes no curso criado pela Biblioteca Nacional, que iniciou suas atividades em 1915 (CASTRO, 2000), visando a uma formação nos moldes de uma escola francesa, de concepções mais humanísticas e eruditas. $\mathrm{O}$ aludido curso "objetivava formar um profissional com o perfil de um erudito-guardião", informa César Augusto Castro. Não foi diferente com o currículo dos primeiros anos da década de 1940, do qual constavam, na área de História, as seguintes disciplinas: Bibliografia, História Literária, Paleografia e Diplomática, Iconografia (CASTRO, 2000). Posteriormente, após as reformas curriculares ocorridas no curso da Biblioteca Nacional, em 1944 e 1962, foram incluídas as disciplinas História do Livro e das Bibliotecas e História da Literatura (CASTRO, 2000). Com a institucionalização do currículo mínimo obrigatório, estabelecido pelo Conselho Federal de Educação, pela Resolução de 16/11/1962, integraram as seguintes disciplinas: História do Livro, História da Literatura, História da Arte, Introdução aos Estudos Históricos, Evolução do Pensamento Filosófico e Científico e Paleografia (CASTRO, 2002, p.36). Aos 
poucos, algumas dessas matérias foram sendo substituídas para adequar o currículo às necessidades de formação de outro profissional em face de uma sociedade com novas exigências no campo do processamento da informação e da organização do conhecimento. Os impactos dessa adequação curricular são observados continuamente pela necessidade de trazer, ao elenco das disciplinas, aquelas que privilegiem a evolução tecnológica, sob pena de o profissional não acompanhar os avanços dos novos saberes da sociedade da informação.

Entretanto, ante a essas novas exigências, como fica o elenco de disciplinas sócio-históricas ainda presentes no currículo que, a cada atualização, perde créditos para aquelas inerentes à área tecnológica? Estamos lidando com uma delicada situação. Se por um lado é necessário acompanhar as mudanças no campo da informação, assim como as exigências da Lei de Diretrizes e Bases da Educação para "enxugar" os currículos dos cursos, por outro, é preciso aproximar o ensino da pesquisa histórica para não nos perdermos em um "tecnicismo informatizado e midiático", que pode levar a um terreno arenoso, sem raízes ou com pouca profundidade. Uma das queixas acadêmicas sempre presentes na área biblioteconômica diz respeito ao pouco aprofundamento teórico na formação do bibliotecário, que privilegia, na maioria das vezes, o lado tecnicista da profissão. Assim, entramos num impasse.

Por conseguinte, o que propomos, neste estudo, é a análise da inserção da pesquisa histórica no elenco das disciplinas do curso, transformando o aluno num leitor/pesquisador/ historiador, se assim podemos dizer, para dar a ele a oportunidade de conhecer profundamente a profissão escolhida, incluindo em sua atividade cotidiana a relação com a história, superando algumas limitações como o desconhecimento da ação profissional e o imediato como referência permanente de uma profissão que já tem milênios.
Lembremos, por exemplo, que há mais de dois mil anos, na Grécia, nasceu Eratóstenes, grande estudioso e pesquisador que, mais tarde, foi convidado para ser professor do filho de Ptolomeu III, o soberano do Egito. Entre os importantes trabalhos por ele realizados, trabalhou como bibliotecário-chefe da Biblioteca de Alexandria, famosa pelas pesquisas desenvolvidas e pela maravilha de acervo lá depositado.

Lá foram escritos os primeiros dicionários e enciclopédias. Foi nos laboratórios de dissecação do museu que um cientista chamado Herofilius identificou, pela primeira vez, a relação entre o batimento cardíaco de uma pessoa e seu pulso e descobriu as diferencias entre artérias e veias.

Foi lá também que um homem chamado Ctesibius inventou o primeiro relógio movido a água, assim como o primeiro instrumento musical com um teclado (LASKY, 2000).

Ao acolher a pesquisa histórica como uma ação pedagógica da ação docente em Ciência da Informação, estaremos associando saberes contemporâneos às lutas travadas pelo conhecimento ao longo da história, suscitando reflexões teóricas indispensáveis à formação discente para superar algumas deficiências nos afazeres do bibliotecário. Evidentemente, não estamos nos referindo a algo produtor de um discurso "salvador" ou de um caminho de mão única, mas a uma possibilidade de que algumas disciplinas possam se utilizar do conhecimento do passado para suscitar nos educandos o desejo da pesquisa e da busca de uma identidade profissional autônoma, não de luta cotidiana por uma causa, mas de definição de respostas para uma ciência que se tornou indispensável às realizações humanas, pois, quando conhecemos nossos "porquês"e nossas razões, nos tornamos 
mais fortes. A História pode contribuir com os alunos na descoberta profissional e na continuidade de seus afazeres dedicados àquele ofício. Trabalhar com a pesquisa histórica, há muito tempo, deixou de ser privilégio dos historiadores, pois, como ensina Marcos A. da Silva, "A história nos permite dialogar com experiências humanas e interpretar seus trajetos, por que não expandir efetivamente o universo das pessoas que desfrutam dessas alegrias?" (SILVA,1995, p.14). Assim, não estamos vislumbrando atuarmos como historiadores, mas pensando que a história pode contribuir em nosso trabalho profissional.

\section{Ensino e Aprendizado por meio da História}

No capítulo Documento/Monumento, da belíssima obra de Jacques Le Goff intitulada História e Memória (LE GOFF,1996), o autor discorre sobre as origens dos termos documento e ensino e da relação que há entre eles. "O termo latino documentum é derivado de docere 'ensinar'. Entretanto, houve uma significativa evolução desses termos, pois os dois também possuem forte ligação ao erudito (doctum). Le Goff afirma: "O documento que, para a escola histórica positivista do fim do século XIX e do início do século $X X$, será o fundamento do fato histórico [...] parece apresentar-se como prova histórica. Além do mais, afirma-se essencialmente como um testemunho escrito" (LE GOFF,1996). Contudo, ao longo do tempo, a noção de documento se atualizou, inevitavelmente, para incorporar outras possibilidades que não apenas o escrito. É justamente com os fundadores da revista Annales d'histoire économique et sociale (1929), pioneiros de uma história nova, que ocorrem as discussões para ampliar a noção de documento, (LE GOFF,1996), pois, mesmo ressaltando-se a importância do documento escrito, perceberam que o conhecimento/história existe independentemente do escrito, dito de diferentes maneiras e de múltiplas possibilidades de leitura e constatação das realizações humanas em vários artefatos e fontes produzidos como: artes em geral, relíquias, depoimentos orais, fotografias, pinturas, jornais, partituras, literatura, imagens etc. Em outras palavras, como diz Febvre, citado por Le Goff, "com tudo que, pertencendo ao homem, depende do homem, serve ao homem, exprime o homem, demonstra a presença, a atividade, os gostos e as maneiras de ser do homem" (LE GOFF,1996).

Rompendo os limites da concepção positivista acerca do conceito de documento utilizado no século XIX, chega-se à conclusão de que parte da Ciência da Informação é constituída de documento e História, pois o registro e a organização dos fatos - dados, informações de um modo geral, gravadas, digitalizadas, escritas, pintadas, imagéticas, para citar alguns - permitem que o conhecimento humano não se perca; inclusive aqueles transmitidos da boca ao ouvido - marca dos antepassados sem escrita ou de povos de tradição oral - correm o risco de se perder no tempo se não forem recolhidos, ou pela falta de registro. A história é contada de várias maneiras, desde as imagens pintadas ou esculpidas pelos antepassados, a medicina popular, as rezadeiras, o folclore, entre outras formas de preservar a tradição, até as possibilidades mais inovadoras de registros tecnológicos. Nesse sentido, o profissional da informação precisa aprender a lidar com um universo informacional das mais diferentes ordens, que vai exigir dele muito esforço e competência. Como trabalhar tantas possibilidades de lidar com a informação sem o rigor da pesquisa histórica na formação desse profissional? O alargamento do conteúdo do termo documentum produziu verdadeira explosão documental a partir dos anos 1960, tanto quantitativa quanto qualitativamente (LE GOFF, 1996) trouxe uma revolução informacional que obrigou bibliotecários a lidarem com o tratamento artesanal e tradicional do documento e, ao 
mesmo tempo, com uma revolução tecnológica produtora de tipos de suportes, que exigiu desse profissional maior capacidade de trabalho, competência e espírito inovador. "Da confluência das duas revoluções nasce a história quantitativa, que põe novamente em causa a noção de documento e o seu tratamento" (LE GOFF,1996). Passou-se também a lidar com um arsenal de informações conectadas por links, relacionadas e seriadas, que diferenciam a atual sociedade caracterizada como sociedade da informação de outras passadas. Vive-se, portanto, uma busca paradigmática para alcançar o futuro antes que ele chegue. Acima de tudo, estamos vivenciando uma "revolução da consciência historiográfica", conclui Furet citado por Le Goff (LE GOFF,1996).

A revolução documental tende também a promover uma nova unidade de informação: em lugar do fato que conduz ao acontecimento e a uma história linear, a uma memória progressiva, ela privilegia o dado, que leva à série e a uma história descontínua. Tornam-se necessários novos arquivos, onde o primeiro lugar é ocupado pelo corpus, a fita magnética. A memória coletiva valoriza-se, institui-se em patrimônio cultural. O novo documento é armazenado e manejado nos bancos de dados. Ele exige uma nova erudição que balbucia ainda e que deve responder simultaneamente às exigências do computador e à crítica da sua sempre crescente influência sobre a memória coletiva.

O fato é que todo esse desenvolvimento trouxe necessidades (inclusive educacionais), de formular novos saberes para a área da Biblioteconomia, antes acomodada em suas práticas, suscitando maior aproximação com a História, a Filosofia e as Ciências Sociais, para fortalecer o aparato tecnológico de conhecimentos que a área tem buscado. Não dá para produzir conhecimento do nada; a teoria se faz necessária, assim como a base empírica e a recorrência aos estudos filosóficos, científicos e historiográficos. Isto porque, mesmo a tecnologia tem suas raízes históricas, apesar de nos remeter ao futuro, não ao passado. Porém, é preciso considerar que as invenções, as produções científicas, os incríveis avanços das pesquisas nas áreas da Medicina, Biologia ou Cibernética são continuidade de estudos que, há séculos, vem sendo desenvolvidos por pesquisadores de outras épocas, resultado de um processo histórico. Lembra Vianney Mesquita que "A história, as comunicações e a cultura, enfim, edificaram um imenso arranha-céu com estrutura para suportar novos andares; teceram uma enorme corrente com o último aro semi-aberto, aguardando receber os grilhões de novos eventos" (MESQUITA, 1989, p.116).

O fato é que a pesquisa histórica ainda é uma tarefa solitária, entretanto, nos oferece um leque aberto de ricas possibilidades no campo do político, do cultural, econômico, social, das idéias, das mentalidades e por aí vai.

Em suma, já é tempo de se começar a buscar no passado da Biblioteconomia mecanismos de compreensão do presente e para o futuro, que se sucedam na formação dos nossos educandos. Conhecimento historiográfico não apenas aquele utilizado nos conteúdos das disciplinas como História do Livro e das Bibliotecas, ou Estudos Históricos, mas como possibilidades de se historiar os saberes relativos à representação social e política da profissão ao longo dos séculos, e o que esses saberes representam no tempo presente, num quadro de práticas que caracterizaram o retrato de uma ocupação que se voltou para as necessidades e anseios de uma sociedade dominante de determinada época, como ocorreu na Idade Média ou em tempos iluminados de Modernidade. Entretanto, mesmo em períodos históricos 
distantes, a luta pelas possibilidades de democratizar a informação já se fazia notória, como nos mostra a História, a exemplo da conhecida bibliothèque bleu, produzida na França através da editoração de textos diversificados que, ao contrário do que geralmente acontecia, tornou acessível ainda no Ancien Régime, escritos para leitores de condição humilde (CHARTIER,1998, p.16). Porém, mesmo na tentativa de uma certa "popularização" bibliográfica, Chartier alerta para o fato de que,

\begin{abstract}
A bibliothèque bleu é uma fórmula editorial que vai beber no repertório de textos já publicados, aqueles que mais parecem convir às expectativas do grande público que ela quer atingir. Donde duas precauções necessárias: não tomar os livros de capa azul como 'populares'em si mesmos, pois eles pertencem a todos os gêneros da literatura erudita; considerar que eles já possuíam uma primeira existência editorial às vezes muito antiga, antes de ter ingressado no repertório de livros para um grande público de leitores (CHARTIER, 1998, p.20).
\end{abstract}

Isto leva a concluir que se tratava de casos isolados e também da tentativa de editores em ampliar sua demanda editorial, utilizando-se da "popularização" de textos não populares, como os gêneros da literatura erudita. Porém, conhecimentos históricos como esse é que levam a reconhecer o papel social do bibliotecário para o enfrentamento das transformações advindas de uma nova ordem econômica de acesso à informação. Hoje, este profissional possuí competências e capacidades diversificadas, plurais e políticas para proceder além dos problemas documentais de classes eruditas, científicas, intelectuais ou dominantes. O papel do profissional em voga reivindica novas atitudes diante da exclusão informacional, dos desníveis educacionais e interage com organismos sociais das mais diferentes categorias: partidos políticos, entidades públicas ou privadas, movimentos sociais, sindicais, igrejas, escolas, associações comunitárias, culturais, entre outras que atendam à sociedade em sua diversidade. Nesse sentido, os educadores têm um papel fundamental na formação discente que diga respeito ao conhecimento histórico através da pesquisa para compreendermos criticamente o que vivemos, o que somos hoje e o que pretendemos para o futuro.

Como incluir os saberes históricos no cotidiano da formação de nossos educandos? Essa é uma questão sobre a qual queremos refletir. Examinemos, pois, o ofício de ensinar em termos de continuidade e transformação. Não estamos começando algo inteiramente novo com o advento da tecnologia (que também possui história, mesmo recente). Partimos de conhecimentos e realizações que possuem profundas raízes históricas de todas as sociedades. É preciso ir além das tensões geradas entre o passado e o presente para buscar os elos e as dimensões históricas. Por exemplo, ordenar o mundo escrito não constituiu no passado e, principalmente agora, uma tarefa muito fácil. $\mathrm{O}$ que se diz, então, de ordenar o conhecimento oralizado, buscado nos "palácios da memória", como diria Santo Agostinho, ou por outro lado, aqueles "tecnologizados", que dispensam o papel para se utilizarem dos meios mais modernos de suportes do conhecimento, muitas vezes transformados num caos documental se não voltar-se para os saberes construídos no passado remoto ou mais próximo? Nessa argumentação, recorre-se a Le Goff (1996, p.13):

Hoje,a aplicação à história dos dados da filosofia, da ciência, da experiência individual e coletiva tende a introduzir, junto destes quadros mensuráveis do tempo histórico, a noção de duração, de tempo vivido, de tempos múlti- 
plos e relativos, de tempos subjetivos ou simbólicos. O tempo histórico da memória, que atravessa a história e alimenta.

O conhecimento é submetido ao tempo em que vivemos, às técnicas que desenvolvemos, à nossa visão de mundo, quer queiramos ou não. Mas, é inevitável que recorramos às experiências vividas e estudadas por nossos antecessores. O que sabemos e aperfeiçoamos hoje são resultados de conquistas passadas, de ações e pesquisas desenvolvidas ao longo da história. É preciso que nossos educandos saibam disso. E nós mesmos.

Nesta mesma perspectiva de reflexão, Edgar Morin leciona que,

Em função desse processo, a situação e o papel da ciência na sociedade modificaram-se profundamente desde o século XVII. $\mathrm{Na}$ origem, os investigadores eram amadores no sentido primitivo do termo: eram ao mesmo tempo filósofos e cientistas. A atividade científica era sociologicamente marginal, periférica. Hoje, a ciência tornou-se poderosa e maciça instituição no centro da sociedade, subvencionada, alimentada, controlada pelos poderes econômicos e estatais. Assim, estamos num processo inter-retroativo (MORIN, 2000, p.19).

Integrando a pesquisa histórica ao ensino, muitos poderão ser os ganhos educacionais e científicos. Por exemplo, ao ensinar Catalogação conhecendo profundamente o material catalogado, pesquisando sobre ele; artefatos pertencentes a diferentes épocas e pessoas: moedas, quadros, fotografias, obras de arte; conhecendo o período e a história de quem os produziu, o que representaram, quais os seus lugares, documentos produzidos etc. Como essa memória/documento contribuiu com o homem de outrora e poderá contribuir com o homem de hoje e o de amanhã!

Outra possibilidade é que, a cada dia, somos surpreendidos por novas formas de registro. Porém, o que parecia ultrapassado há algumas décadas, vêm recebendo especial atenção por parte de historiadores, pesquisadores, sociólogos, entre outros, como fonte privilegiada de informação e, portanto, tornou-se indispensável o estabelecimento de operações para o seu ordenamento, como acervo: as fontes orais. Como trabalhar com essas fontes sem conhecê-las? Não é possível nos limitarmos apenas ao aspecto técnico. Há todo um conjunto que precisa ser levado em consideração. Cada depoimento narrado, por exemplo, é produto de uma história de vida, de uma visão de mundo, de um estatuto social de determinada época, de uma cultura. Quem sabe, o trabalho com esse tipo de fonte não será a vocação de muitos dos nossos educandos? Tantos projetos e programas de constituição de acervos orais têm sido desenvolvidos no Brasil, como o Centro de Pesquisa e Documentação de História Contemporânea do Brasil (CPDOC), da Fundação Getúlio Vargas no Rio de Janeiro, viabilizando a geração e o acesso a determinadas informações por parte de pesquisadores que, de outro modo, não poderiam realizar suas pesquisas. É preciso estarmos preparados também para esse mercado profissional.

Nesse sentido, o exercício da pesquisa histórica e da prática durante a formação profissional se tornam mecanismos indispensáveis, visando à interação do conjunto de experiências vividas e estudadas, dentro e fora da sala de aula, pois, como sugere Marcos A. da Silva (1995, p.19):

Identificar pesquisa e ensino significa preservar o rigor da produção do saber, próprio à primeira, e o compromisso de sua presença na cena social 
ampliada e sob controle de seus agentes, inerente ao segundo, pensando numa síntese desses atributos. Nesse sentido, há reciprocidade na aliança (ensino e pesquisa se iluminam, ampliam e superam simultaneamente) e garantia de que os atos de pesquisar e ensinar continuam a se questionar permanentemente em busca de novos horizontes na produção de saberes.

Uma das formas de se fazer pesquisa histórica no ensino é através de atividades realizadas fora da sala de aula em arquivos públicos ou museus, ou trabalhos junto a comunidades para colher depoimentos de sindicalistas, ex-presos políticos, educadores ou de pessoas comuns, lidando com fontes orais, que abrem possibilidades para pesquisadores nas Ciências Humanas, principalmente. Infelizmente, são poucos os Centros de Informação, no Brasil, cujas pesquisas em fontes primárias ainda não sejam realizadas de forma artesanal e manual, porém, "[...] exigindo esforço e tempo dos pesquisadores, os arquivos históricos, depositários dessas fontes, vêm sendo pressionados a se modernizarem diante da rapidez das inovações tecnológicas que revolucionaram a produção e disseminação de informações e das novas exigências de rapidez na produção de teses e na conclusão dos resultados de pesquisas" (ARAÚJO, 1999, p.75).

Destacamos, também, o jornal como fonte privilegiada da história e do fazer bibliotecário sobre o cotidiano, ao qual costuma-se dar pouca atenção, sendo insignificante sua utilização como material didático no ensino e na pesquisa. Através desse periódico diário, já utilizado há séculos pela sociedade, tem-se ricos documentos de reconstrução do passado em suas diferentes nuanças.

Dia a dia, ano a ano, década a década, o século que conheceu a expansão tecnológica da imprensa poderia ser revisto por qualquer pesquisador interessado em conhecer o presente através de um evolver pleno de sinais de continuidade e descontinuidade, que tão bem caracterizam o movimento da história (CAVALCANTE, 2000).

No jornal, encontra-se acontecimentos dos mais variados sobre a realidade social locais, nacionais e internacionais que nos permitem um acompanhamento de fatos traduzidos por uma linguagem jornalística peculiar, rápida e cronológica, em sua universalidade para causar impacto social, oferecendo ainda uma série de possibilidades de temas para pesquisas e questionamentos dessa e de outras épocas.

Especial atenção merece o patrimônio histórico no ensino e na pesquisa. Estudá-lo não é privilégio apenas dos historiadores, principalmente porque está relacionado com o passado e o cotidiano de todos. O patrimônio histórico é o resultado da enorme diversidade das construções humanas, materiais ou imateriais, desde os mais tradicionais, como os centros históricos tombados oficialmente, até o mais próximo das experiências de cada um, que representam identidades étnicas, culturais, familiares ou populares. Assim, lida-se com acervos formadores de cidadania, a partir de suas histórias, conquistas ou derrotas que ampliam a noção de documento, mais uma vez, pela informação que esses espaços possuem.

A defesa do prazer da história que englobe a questão do patrimônio histórico precisa dar conta, então, de dois problemas básicos: por um lado, o respeito às múltiplas formas de ser social como portadoras de identidades ricas e significativas para a compreensão de um mundo que se faz em muitos lugares e por diferentes 
agentes, entendendo que a educação se dá tanto em seus espaços formais (escolas, museus, bibliotecas) como fora deles - movimentos sociais, cotidiano de sobrevivência; por outro, a garantia de acesso a patrimônios daqueles espaços formais de educação como dimensões das experiências permanentes de formação e lazer para todos, ultrapassando faces apenas simbólicas, retóricas e distantes de que se revestem tantos de seus itens para a maioria das pessoas (SILVA, 1995, p.53).

Todas essas argumentações em defesa da pesquisa histórica no ensino significa uma tentativa de aproximar os saberes acadêmicos daqueles cotidianos, das várias identidades culturais e sociais, das diferentes vozes murmuradas, gritadas ou silenciadas ao longo da memória preservada, ou do que ainda resta dela, em alguns casos. É uma tentativa, também, de aprofundamento dos conteúdos transmitidos em sala de aula, de informações imediatas, fugidias ou mesmo cristalizadas. Não dá para compreender, nos tempos atuais, um ensino pautado apenas na transmissão linear de conhecimentos sem uma efetiva interação com o universo dos saberes estudados e o alargamento de horizontes por parte de professores e alunos. O aprendizado é um caminho de mão dupla, à medida que se ensina, também se aprende. Quais os questionamentos que nos permitimos fazer acerca daquilo que integra o conteúdo das disciplinas? Ou sobre o legado biblioteconômico deixado por nossos antecessores, ou ainda, sobre posições conservadoras, modernas, políticas, impostas, censuradas, ideologizantes? Estamos permi-tindo aos nossos educandos o exercício de um pensamento criativo, autônomo e crítico acerca da realidade discutida em sala? Ou incentivamos a submissão e a passividade em relação a estilos consagrados de conhecimento?

O processo educativo não ocorre de modo isolado. Agora, mais do que nunca, a interdisciplinaridade tornou-se exigência de qualquer currículo, assim como a relação indispensável do processo educacional com outras ciências como a História, a Sociologia, a Filosofia, a Antropologia, para citar algumas, de um elenco que possibilita ampliar a compreensão dos mecanismos diversos da construção do saber e da produção do conhecimento científico, produzidos em todas as disciplinas no campo da Ciência da Informação, sob a perspectiva de formação de um profissional que acentua a diversidade necessária. Porém, é importante salientar, que não se trata de criar referentes fixos ou de padrões pré-estabelecidos a partir de outras áreas, pois, a mudança constante do conhecimento - característica dessa sociedade - lança uma pluralidade que não deixa espaços para modelos prévios, e sim favorece a interação entre os vários campos do saber e sua complexidade em relação aos fenômenos sócio-históricos e as possibilidades de apreensão do real.

Diferentes situações de aprendizagem devem ser desenvolvidas e introduzidas no campo do ensino, relacionando o acesso ao saber com a história e a pesquisa. Tudo depende, evidentemente, da formação do próprio educador e de como ele está lidando com as novas exigências no campo da educação, que vão além do repasse de conteúdos. Do processo educativo fazem parte a prática reflexiva, a análise crítica, a autonomia e a delegação de responsabilidades ao educando sobre a sua formação. É preciso descentralizar os saberes, suscitando o desejo de aprender, incentivando a elaboração de um projeto pessoal por parte dos educandos. Nenhum conhecimento, em sua complexidade, é absoluto ou eterno, há sempre uma relação com outros saberes, com novas aquisições do pensamento, ou mesmo de valores. O sentido 
da relação mestre e discípulo, na qual o primeiro ensina e o segundo aprende, há muito tempo deixou de ser um modelo de educação válido para os tempos atuais. $O$ aprendizado de cada um, especialmente na universidade, é de responsabilidade do próprio aluno e o professor é um colaborador desse processo. Daí por que o docente deve envolver o aluno em projetos e atividades de pesquisa e extensão, espaços de discussões e várias outras atividades além da sala de aula para que ele elabore as próprias perguntas e respostas.

\section{RE FERÊ N C I A S}

ARAÚJO, A.; BATALHA, C.H.M. Preservação da memória e pesquisa: a experiência do arquivo Edgard Leuenroth (AEL). In.: SILVA (Org.) Arquivo, Patrimônio e memória: trajetórias e perspectivas. São Paulo: UNESP, 1999. 65-77p.

CASTRO, C.A. História da Biblioteconomia Brasileira: perspectiva histórica. Brasília: Thesaurus, 2000. p.53-62,85,100

CASTRO. C.A. Histórico e evolução curricular na área de Biblioteconomia no Brasil. In.: VALENTIM, (org.). Formação do profissional da informação. São Paulo: Polis, 2002. p.25-48.

CAVALCANTE, M.J.M. O Jornal como fonte privilegiada de pesquisa histórica no campo educacional. Fortaleza: [s.n.], 2000.

CHARTIER. R. A Ordem dos livros: leitores, autores e bibliotecas na Europa entre os séculos XIV e XVIII. 2.ed. Brasília: UNB, 1998. p.16-20.
HOBSBAWN. E. Sobre História. São Paulo: Companhia das Letras, 1998.

LASKY, K. O Bibliotecário que mediu a terra. Rio de Janeiro: Salamandra, 2000.

LE GOFF. J. História e memória. 4.ed. Campinas: Unicamp, 1996. p.13, 536, 539, 540

MESQUITA. V. Impressões: estudos de literatura e comunicação. Fortaleza: Imprensa Universitária/UFC, 1989. p.116.

MORIN. E. Ciência com consciência. 4.ed. Rio de Janeiro: Bertrand Brasil, 2000. p.19

PERRENOUD. P. 10 Novas competências para ensinar. Porto Alegre: Artes Médicas, 2000.

SILVA. M.A. História: o prazer em ensino e pesquisa. São Paulo: Brasiliense, 1995. 